\title{
Medical internship training in Saudi Arabia: interns' views and perceptions
}

This article was published in the following Dove Press journal:

Advances in Medical Education and Practice

31 January 2017

Number of times this article has been viewed

\author{
Ali I Swaid' \\ Abdelkhalig $\mathrm{H}$ Elhilu² \\ Mohamed S Mahfouz ${ }^{3}$ \\ 'Department of ENT, Faculty \\ of Medicine, Jazan University, \\ ${ }^{2}$ Department of Surgery, Faculty \\ of Medicine, Jazan University, \\ ${ }^{3}$ Department of Family and \\ Community Medicine, Faculty of \\ Medicine, Jazan University, Jazan, \\ Saudi Arabia
}

Correspondence: Mohamed S Mahfouz Department of Family and Community Medicine, Faculty of Medicine, Jazan University, PO Box 253I, Jazan 45I42, Saudi Arabia

Email mm.mahfouz@gmail.com
Background: Internship training offers an important opportunity for personal development and career planning. However, there are many factors affecting the efficiency of training, and the views of interns are rarely considered. The main objective of this study was to explore the views of interns enrolled in Jazan University internship program during the year 2015.

Subjects and methods: A web-based cross-sectional study was conducted in the Jazan region, Kingdom of Saudi Arabia, during the academic year 2015. To achieve the study goals, an online questionnaire was distributed to all interns $(n=85)$ enrolled in the Jazan University internship program. Results: Results revealed that satisfaction with training was more evident in general surgery and pediatrics $(76.1 \%, \mathrm{n}=54$ and $77.5 \%, \mathrm{n}=55$, respectively). Satisfaction was lowest for obstetrics and gynecology programs $(45.1 \%, n=32)$, while in internal medicine it was $54.9 \%(n=39)$. Training in general surgery and pediatrics was rated as excellent by most of the interns ( $45.8 \%$ and $43.1 \%$, respectively). The picture is reversed in obstetrics and gynecology, as $43.1 \%$ rated it as average. More than half of the study sample felt that they were well prepared to start the next step in their career at the end of internship (50.7\%), while $25.4 \%$ felt that they were moderately prepared.

Conclusion: It is clear that training quality in views of interns is variable across the major specialties, and there are some problems in obstetrics and gynecology training. More studies are needed to explore in-depth dimensions of internship training program in the Kingdom of Saudi Arabia. Keywords: Jazan University, internship program, gynecology and pediatrics

\section{Introduction}

Internship training, in spite of its transient nature, offers an important opportunity for personal development and career planning. ${ }^{1}$ Medical internship has undergone many innovations since its inception in the middle of the last century. ${ }^{2}$ In Saudi Arabia, it extends to a 12-month period of supervised training in different specialties: 2 months duration in general surgery, internal medicine, pediatrics, obstetrics and gynecology, and family medicine (1 month), which are known as core rotations are mandatory, and the rest of the period is spent in elective rotations. ${ }^{3}$ Medical colleges oversee internship programs and have the freedom to modify the elective rotations. During this period, the intern is supposed to master skills and consolidate his medical knowledge as well as deliver patient service under supervision.

Literature suggested that many factors affect the efficiency of training. ${ }^{4}$ The tendency to treat patients on outpatient basis, the increasing use of day surgery, and the increasing patient awareness in addition to cultural factors have affected the experience of the trainee. ${ }^{1}$ Furthermore, the increasing number of litigations has affected those who supervise interns 
as they become more reluctant to give interns responsibilities that offer them the chances to practice medical skills. ${ }^{5}$

It has been shown by many studies elsewhere that an intern's satisfaction with training varies widely at the institute level and at different clinical rotations. ${ }^{6-8}$ Determinants of effective training associated with an intern's satisfaction include a wide variety of factors. Quality of supervisors, effective supervision, adequate opportunity to experiential learning, conducive environment, good support system (hospital management, hospital staff, academic opportunities), personal attributes, and reasonable workload are some of the factors highlighted by some authors. ${ }^{9,10}$ On the other hand, maltreatment and abuse of interns, which is very common worldwide, ${ }^{11-13}$ might have a negative impact on intern satisfaction and the outcome of internship in general. In Saudi Arabia, Iftikhar et $\mathrm{al}^{14}$ showed that abuse and maltreatment are very common among interns.

Studies addressing Internship training are very scarce in Saudi Arabia. The main objective of this study was to explore the views and perceptions of the interns enrolled in Jazan University internship program during the year 2015 regarding their insight and career orientation, satisfaction with training, and the degree of preparedness to start the next step in their career at the end of internship.

\section{Subjects and methods Study place}

The study was conducted in the College of Medicine, Jazan University. This university is the leading higher educational institution in the region. Jazan region is one of the 13 administrative regions of Saudi Arabia. The total area of the region is estimated at $40,457 \mathrm{~km}^{2}$, and the total population is around 1.5 million. The College of Medicine was established in 2001 in Jazan town with the main purpose of graduating qualified doctors who will participate actively in the medical services in the region and the country at large. The college oversees the internship program for its own graduates as well as medical graduates from other universities who are enrolled in it.

\section{Study design and participants}

The study was an observational cross-sectional survey that targeted all medical graduates who were doing their internship training under the auspices of Jazan University Faculty of Medicine in the year 2015. Data collection was done based on full census, as all interns enrolled in the internship program were considered eligible for participating in this survey $(n=85)$.

\section{Data collection}

A standardized web-based questionnaire was designed for data collection after consulting previous studies., ${ }^{415}$ The questionnaire consisted of two sections. The main section evaluated respondents' satisfaction toward their internship experience. There were 20 internship variables measured. Respondents were requested to give a score to each of the 20 variables using a 5-point Likert-type scale. The Likert scale was used with $1=$ not satisfied, $2=$ =slightly satisfied, $3=$ moderately satisfied, $4=$ very satisfied, and $5=$ extremely satisfied. Likert scores of 1 and 2 were combined as unsatisfied, while Likert scores 4 and 5 were combined and considered satisfied. The demographic questionnaire covered age, gender, and university from which the intern graduated. Other information such as prior idea about the training, orientation workshops, and degree of preparedness were also taken into consideration.

\section{Data management and analysis}

The data entry and analysis were performed using SPSS (version 17 Inc., Chicago, IL, USA) software. Descriptive statistics as well as inferential statistics was used for data analysis. Data are presented as percentage of respondents answering 1 and 2 or 4 and 5 on the Likert scale for preparation and importance ratings. The association between gender and level of satisfaction with the different specialties was assessed using the chi-square test. A $P$-value of 0.05 or less was used as the cutoff level for statistical significance.

\section{Ethics approval and consent to participate}

This study was conducted in accordance with ethical standards within the political borders of the Kingdom of Saudi Arabia. Participants were told that they had the freedom to participate or to withdraw from the study at any time. The anonymity of participants was emphasized, and confidentiality was strictly maintained on all collected questionnaires. The study was approved by the Committee of Faculty of Medicine - Jazan University Saudi Arabia and all the students included in the study completed an electronic consent form before the start of the study.

\section{Availability of data and materials}

The datasets generated during and/or analyzed during the current study are available from the corresponding author on reasonable request.

\section{Results \\ Background of study participants}

A total of 71 interns out of 85 responded to an online questionnaire (83.5\% response). The vast majority of the interns (94.4\%) are graduates of Jazan University. Around $56.3 \%$ of the respondents were females, while $(43.7 \%)$ were males (Table 1$)$. 
Table I Background characteristic of the study population

\begin{tabular}{lll}
\hline Characteristics & Number & $\%$ \\
\hline Gender & 31 & 43.7 \\
$\quad$ Male & 40 & 56.3 \\
$\quad$ Female & & \\
Nationality & 70 & 98.6 \\
$\quad$ Saudi & 1 & 1.4 \\
$\quad$ Non-Saudi & & \\
Age groups (years) & 54 & 75.6 \\
$20-24$ & 17 & 24.4 \\
$25+$ & & \\
University of graduation & 67 & 94.4 \\
Jazan & 4 & 5.6 \\
Other university & & \\
Year of graduation & 1 & 1.4 \\
2013 or earlier & & 73.2 \\
2014 & 52 & 25.4 \\
2015 & 18 & 100 \\
\hline Total & 71 & \\
\hline
\end{tabular}

Table 2 Interns' attitudes toward orientation workshop on specialty choosing activities attended during internship period

\begin{tabular}{lll}
\hline Characteristics & Number & $\%$ \\
\hline Prior idea about different rotations & & \\
I had full idea & 9 & 12.7 \\
I had no idea & 11 & 15.5 \\
I had some idea & 51 & 71.8 \\
Source of your idea & & \\
Workshops & 12 & 16.9 \\
Internet & 14 & 19.7 \\
Senior colleague & 40 & 56.3 \\
Was the orientation workshop of a benefit to you & & \\
Extremely beneficial & 0 & 0 \\
Very beneficial & 10 & 13.9 \\
Moderately beneficial & 23 & 31.9 \\
Slightly beneficial & 12 & 16.7 \\
Not beneficial at all & 27 & 37.5 \\
Was the workshop on specialty choosing helpful to you & & \\
Extremely beneficial & 4 & 5.6 \\
Very beneficial & 17 & 23.6 \\
Moderately beneficial & 17 & 23.6 \\
Slightly beneficial & 14 & 19.4 \\
Not beneficial at all & 12 & 16.7 \\
Did not attend & 8 & 11.1 \\
Total & 71 & 100 \\
\hline
\end{tabular}

\section{Insight and career orientation}

Interns were asked whether they have a prior idea about what to expect (responsibilities during the different rotations before starting their internship program). They were also asked to point out the source of that idea from a number of options. As can be seen from the data in Table 2, the vast majority of the study group (71.8\%) mentioned that they had some idea about internship prior to its start, while $15.5 \%$ stated that they have no idea. Most of the interns got their knowledge about internship from senior colleagues (56.3\%), 19.7\% searched the Internet to get information, and only $16.9 \%$ got their information from workshops.

A mandatory orientation workshop addressing internship and training issues is organized every year for all interns before enrolling in their internship rotations. Opinions are divided about this workshop as a significant proportion of interns found it not beneficial at all (37.5\%). Around 16.7\% think that it was slightly beneficial, while $31.9 \%$ found it moderately beneficial, and $13.9 \%$ think that it was very beneficial. However, no one thought that it was extremely beneficial (Table 2).

Another workshop (nonmandatory) addressing career advice is organized every year just before graduation. Interestingly, opinions about this workshop are more divided and follow an almost normal distribution varying from extremely beneficial to not beneficial at all (Table 2).

\section{Satisfaction with training and level of preparedness}

Satisfaction with training showed significant variation of opinions across the major specialties $(P<0.0001)$. Around $76.1 \%$ stated that they were satisfied with their training in general surgery, and $12.7 \%$ were moderately satisfied, while $11.3 \%$ expressed their dissatisfaction with training. In internal medicine, $54.9 \%$ were satisfied with their training, 35.2\% were moderately satisfied, and 9.9\% were dissatisfied. Only $45.1 \%$ were satisfied with training in obstetrics and gynecology, 25.4\% moderately satisfied, and $29.6 \%$ expressed their dissatisfaction; the highest percentage compared to the other specialties. However, satisfaction with training was highest in pediatrics with $77.5 \%$ satisfied, $22.5 \%$ moderately satisfied, and remarkably, no one expressed dissatisfaction. There is no significant statistical difference between males and females regarding satisfaction with training in the different specialties $(P>0.05)$ (Table 3$)$. More details regarding the level of satisfaction with training are shown in Figure 1.

When asked to give a rating to the quality of training in the different specialties, the study sample responses are consistent with their satisfaction. General surgery and pediatrics received the highest rating as excellent $(45.8 \%$ and $43.1 \%$, respectively). Opinions were divided when rating the quality of training in internal medicine; around $34.7 \%$ gave an excellent rating, while $31.9 \%$ rated it as average. Dissatisfaction was clear in the rating of obstetrics and gynecology as $43.1 \%$ rated it as average and only $20.8 \%$ claimed that it was excellent (Figure 2).

When asked whether they felt prepared to start their future career training, more than half of the interns stated 
Table 3 Interns' level of satisfaction with training in the different specialties

\begin{tabular}{|c|c|c|c|c|c|c|c|c|c|c|c|}
\hline \multirow[t]{2}{*}{ Specialties } & \multicolumn{3}{|l|}{ Male } & \multicolumn{3}{|l|}{ Female } & \multirow[t]{2}{*}{$P$-value } & \multicolumn{3}{|l|}{ Total } & \multirow[t]{2}{*}{$P$-value } \\
\hline & Unsatisfied & M. Satisfied & Satisfied & Unsatisfied & M. Satisfied & d Satisfied & & Unsatisfied $^{\mathbf{a}}$ & M. Satisfied & Satisfied ${ }^{b}$ & \\
\hline General & $4(12.9)$ & $2(6.5)$ & $25(80.6)$ & 7 (I7.5) & $4(10.0)$ & $29(72.5)$ & 0.322 & $8(11.3)$ & $9(12.7)$ & $54(76.1)$ & 0.000 \\
\hline \multicolumn{12}{|l|}{ Surgery } \\
\hline Internal & $2(6.5)$ & $12(38.7)$ & $17(54.8)$ & $5(12.5)$ & $13(32.5)$ & $22(55)$ & 0.081 & $7(9.9)$ & $25(35.2)$ & 39 (54.9) & \\
\hline \multicolumn{12}{|l|}{ Medicine } \\
\hline Obstetrics and & $9(29)$ & $12(38)$ & $10(32.3)$ & $12(30)$ & $6(15)$ & $22(55)$ & 0.067 & $21(29.6)$ & $18(25.4)$ & $32(45 . I)$ & \\
\hline \multicolumn{12}{|c|}{ Gynecology } \\
\hline Pediatrics & $0(0)$ & $8(25.8)$ & $23(74.2)$ & $0(0)$ & $8(20)$ & $32(80)$ & 0.592 & $0(0)$ & $16(22.5)$ & $55(77.5)$ & \\
\hline
\end{tabular}

Notes: ansatisfied includes not satisfied and slightly satisfied; bsatisfied includes very satisfied and moderately satisfied.

Abbreviation: M, moderately.

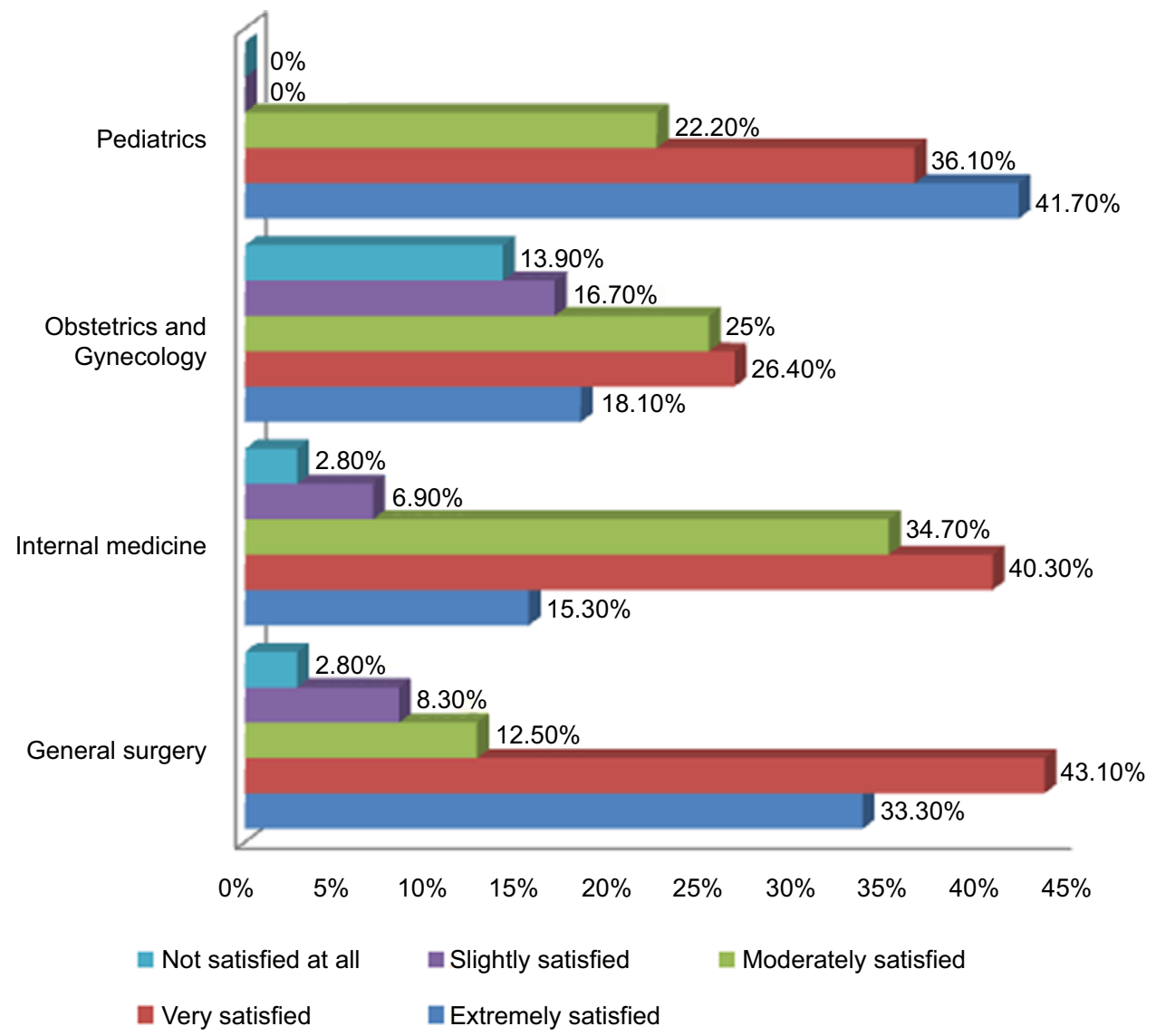

Figure I Interns' level of satisfaction with the training in the different specialties.

that they were well prepared (57.5\% males, $41.9 \%$ females). Approximately $25.8 \%$ of the interns mentioned that they were moderately prepared. There was no significant statistical difference between males and females regarding preparedness. Interestingly, two female interns stated that they were not prepared at all (Figure 3).

\section{Discussion}

The primary purpose of internship is to offer practical work experience in the health facilities setup. It is a transitional period where medical graduates acquire the necessary skills and credentials needed to pursue their future careers. In the final years of medical college, medical students are faced with the uncertainty of the prospect of their professional careers. The impact of internship experience on the choice of future specialty is not clear. Alshahrani et a $1^{15}$ found $11.4 \%$ of their study population of interns citing their internship experience as the main reason in specialty choice.

In our study, most of the interns had some idea about what to expect from an internship, although the source of this idea was mostly senior colleagues. Many authors highlighted the lack of career advice for medical students. ${ }^{16,17}$ In Saudi 


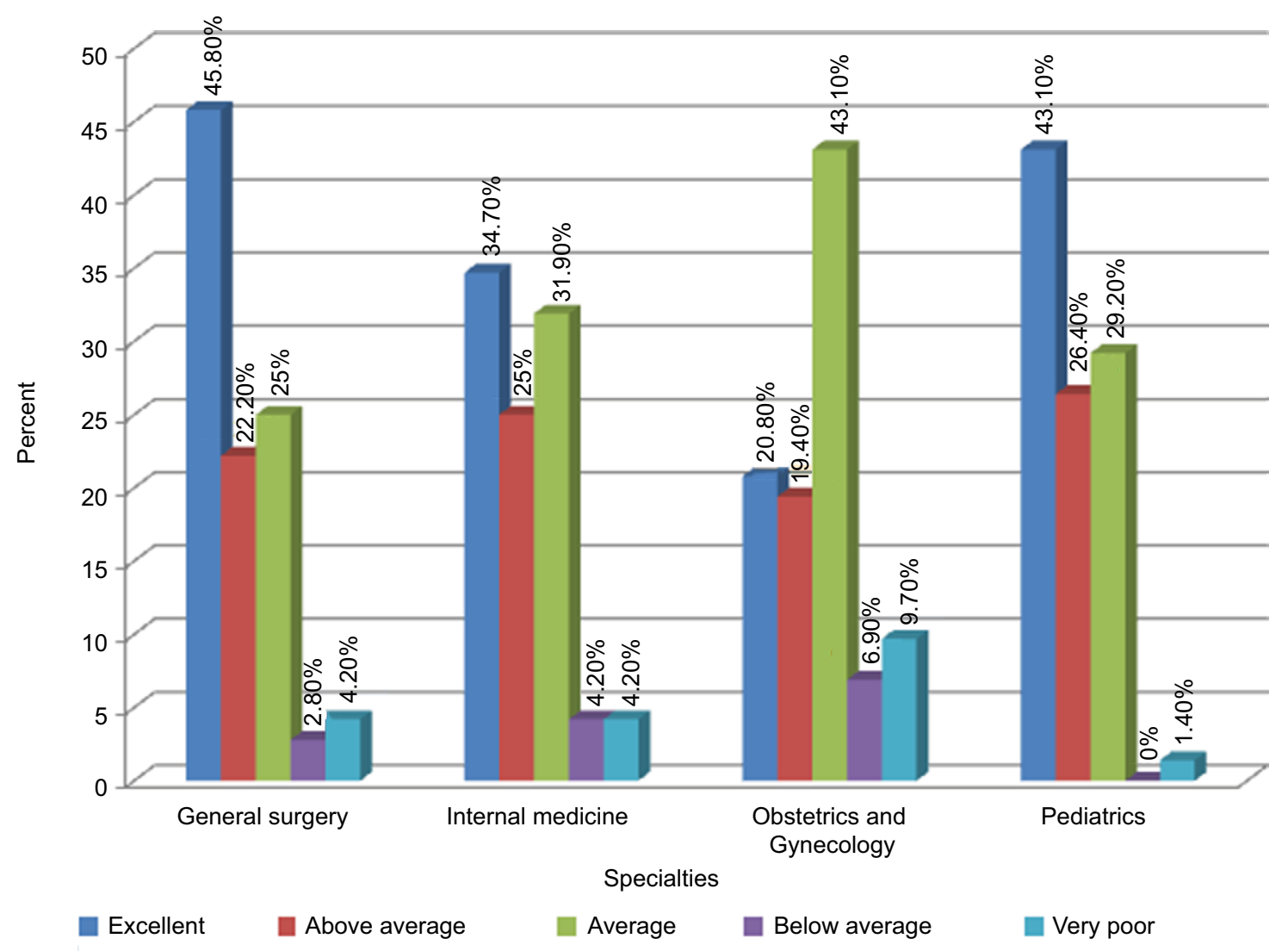

Figure 2 Interns' views about the quality of training in the different specialties.

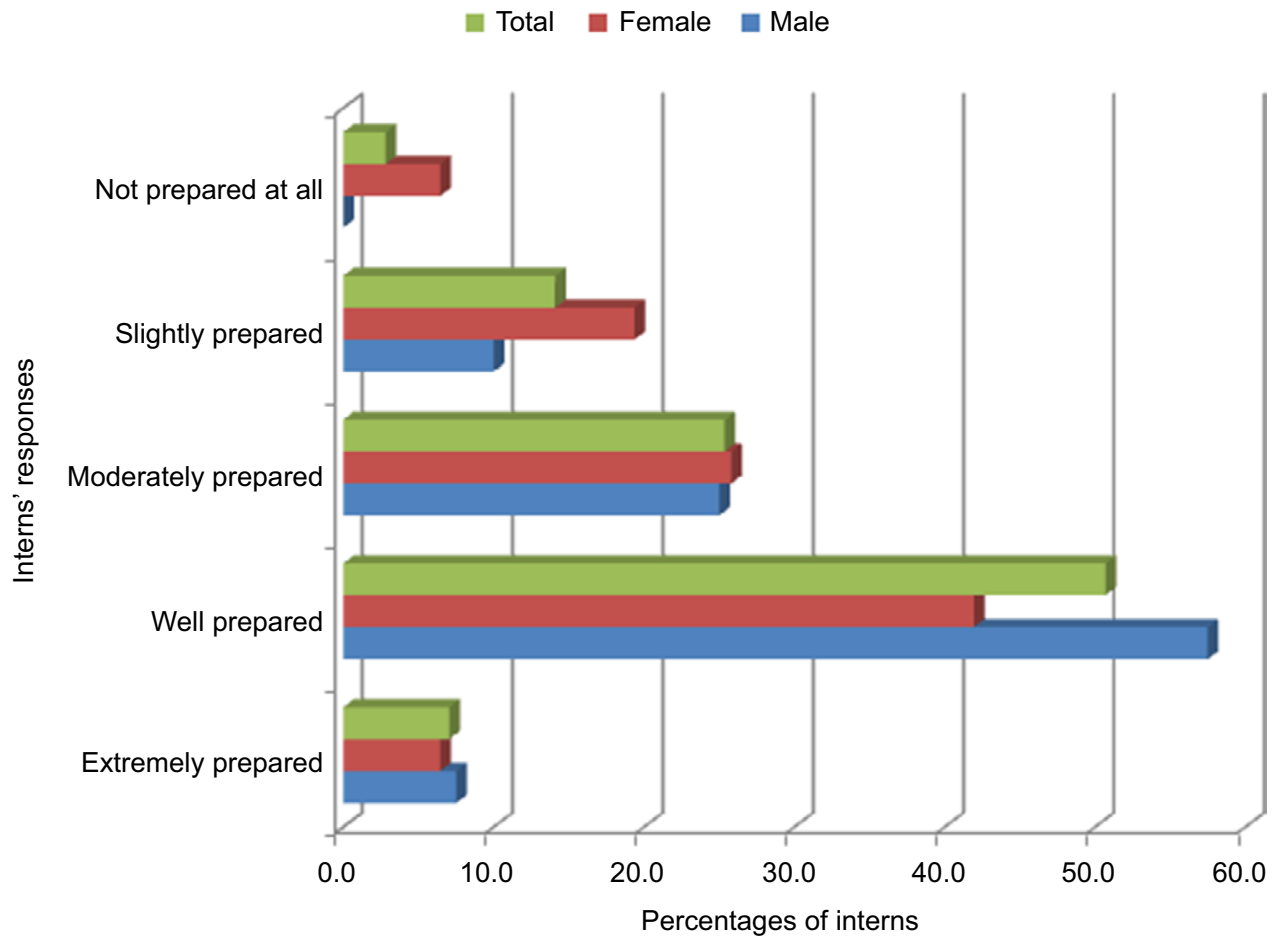

Figure 3 Interns' views regarding level of preparedness for the next step in their career.

Arabia, Mehmood et al ${ }^{4}$ found that only $53 \%$ of the study participants received career advice. However, this career advice was not structured as it consisted of advice from family members, friends, and senior colleagues. Many authorities have developed measures to prepare medical students for internships. Induction courses, transition courses, a preintern 
year, and Tomorrow's doctorscurriculum (general medical council, UK) are a few examples of these measures. ${ }^{18-21}$

In Jazan University, we used to organize a workshop every year for new medical graduates providing career advice. Another workshop, which is mandatory, aims to orient the students about the internship and is organized every year by Jazan Training Administration. Opinions about this workshop are also divided. In spite of this, it seems that the content of these workshops is not up to the expectations of a significant proportion of our interns. This shows the importance of structuring career guidance and advice and even considering its incorporation in the medical curricula. ${ }^{18}$

Satisfaction with training is influenced by many factors either negatively or positively. ${ }^{11}$ Opinions about the adequacy of training, and hence satisfaction with it, vary a lot. Elizabeth and Hughes found $94 \%$ of preregistration house officers qualifying at Liverpool University rating their training as adequate. ${ }^{22}$ Formal education and training during the internship year in Ireland were found to be poor, as evidenced by the study by Hannon. ${ }^{23}$ Our search could not cite any article addressing this issue in Saudi Arabia. In our study, we addressed the issue in more details considering training satisfaction and adequacy of training in general surgery, internal medicine, obstetrics and gynecology, and pediatrics. Satisfaction was highest in general surgery and pediatrics and lowest in obstetrics and gynecology, while in internal medicine mixed opinions were obtained. This was evident when the interns were asked to rate their training: most of them rated training as excellent in general surgery and pediatrics, while almost half of them thought it was average in obstetrics and gynecology. It is well known that good training brings satisfaction, and vice versa. This will be an oversimplification if we assume that it is the only reason. A declining interest in obstetrics and gynecology has been observed by some authors, and many students have a poor perception of their obstetrics and gynecology clerkships. ${ }^{24-26}$ Obstetrics and gynecology clerkship factors associated with greater postclerkship interest include higher satisfaction with the resident's professional behavior and the students' sense of inclusion in the clinical team. ${ }^{25}$ We think similar factors may be affecting our interns. Although the opinions about the other specialties appear favorable, that does not mean there are no problems. The factors influencing satisfaction were not highlighted in our study. More studies are needed to assess the training adequacy across the specialties in Saudi Arabia and look in more details as to why training in obstetrics and gynecology is less satisfactory.

After successfully completing the internship period, interns are expected to acquire a level of knowledge, skills, and attitudes needed to embark on a career as a health care provider, or to pursue further training in a medical specialty. ${ }^{27}$ Furthermore, working in clinical environment allows interns the opportunity to measure themselves and see where they stand regarding the level of knowledge and skills compared to fully registered doctors. Feeling confident in performing clinical and procedural skills and initiating management of different clinical conditions is important in the perceived preparedness for further career commitments. ${ }^{28}$ In a wide scale survey, Blumenthal et $\mathrm{al}^{29}$ found the vast majority of their population either very prepared or somewhat prepared. Nkabinde et $\mathrm{a}^{30}$ found that $78 \%$ of the interns rated their internship as good or excellent in preparing them for community service.

To our knowledge, this aspect of internship has not been studied in Saudi Arabia. Our study focused on overall preparedness of interns without going into details. We tried to find whether medical college and internship training experience has prepared interns for the next step of their career. Most of our study population felt that they were well prepared, moderately prepared, or extremely prepared $(41.9 \%, 25.8 \%$, and $6.5 \%$, respectively, total $74.2 \%$ ). On the other hand, some of the interns felt that they were slightly prepared or not prepared at all (19.4\% and 6.5\%, respectively). Our results, and that of many other studies, confirm that internship is very important in career development. However, these results should be interpreted carefully as the question of preparedness is a complex one and there are many aspects of internship experience that need to be considered individually and separately for better understanding..$^{31,32}$

\section{Limitations}

The strength of this study is that it is the first study in the Kingdom of Saudi Arabia that focuses on intern's views on the internship training program. Despite this strength, the study has some limitations that should be mentioned to facilitate the proper understanding of the outcomes. First, because the work was based on a cross-sectional survey design, the direction of relationships and causal relationships could not be determined. Second, the sample size was small $(n=71)$ and represented only one academic year. It also did not represent all geographical areas of Saudi Arabia. However, it can represent a trend in the country as the cultural background and the infrastructure of medical training remain the same.

\section{Conclusion}

From this study, we conclude that a significant proportion of interns lack orientation about what to expect from 
internship and that the main source of information is senior colleagues, highlighting the need for structured career advice. It is also clear that the training quality is variable across the major specialties and that there are some problems in obstetrics and gynecology training. It is also clear that satisfaction is enhanced by a perceived good training, and internship training remains very important in preparing doctors for their future careers. We think that internship in Saudi Arabia is an important area that needs to be targeted with more studies.

\section{Acknowledgment}

The authors are grateful to Dr Nader Wahba and Mr Vikrant for helping with the design of the online questionnaire.

\section{Author contributions}

All authors contributed toward data analysis, drafting and critically revising the paper and agree to be accountable for all aspects of the work.

\section{Disclosure}

The authors report no conflicts of interest in this work.

\section{References}

1. Moss F. The pre-registration year. Med Educ. 1997;31(Suppl 1):10-11.

2. Al-Moamary MS, Mamede S, Schmidt HG. Innovations in medical internship: benchmarking and application within the King Saud bin Abdulaziz University for Health Sciences. Educ Health (Abingdon). 2010; 23(1):367.

3. Almahfouz NF, Aldaher AS, Algha OI. Medical specialty selection Guide for medical graduates, Saudi commission for health specialties, 2015. Available from: http://www.scfhs.org.sa/Media/OtherPublications/Documents/Medical\%20Guide\%20Complete\%2031.3.15.pdf. Accessed August 30, 2016.

4. Mehmood SI, Norcini JJ, Borleffs JC. Newly qualified doctors' views on the significance and accessibility of career advice during medical training in Saudi Arabia. Med Teach. 2013;35(Suppl 1): S20-S24.

5. Reed DA, Windish DM, Levine RB, Kravet SJ, Wolfe L, Wright SM. Do fears of malpractice litigation influence teaching behaviors? Teach Learn Med. 2008;20(3):205-211.

6. Gillard JH, Dent TH, Aarons EJ, Smyth-Pigott PJ, Nicholls MW. Preregistration house officers in eight English regions: survey of quality of training. BMJ. 1993;307(6913):1180-1184.

7. Clack GB. Medical graduates evaluate the effectiveness of their education. Med Educ. 1994;28:418-431.

8. Goldacre MJ, Lambert TW, Parkhouse J. Views of doctors in the United Kingdom about their own professional position and the National Health Service reforms. J Public Health Med. 1998;20(1):86-92.

9. Sein N, Tumbo J. Determinants of effective medical intern training at a training hospital in North West Province, South Africa. African J Health Prof Educ. 2012;4(1):10-14.

10. Cannon GW, Keitz SA, Holland GJ, et al. Factors determining medical students' and residents' satisfaction during va-based training: findings from the VA Learners' Perceptions Survey. Acad Med. 2008;83(6): 611-620.
11. Daugherty SR, Baldwin DC Jr, Rowley BD. Learning, satisfaction, and mistreatment during medical internship: a national survey of working conditions. JAMA. 1998;279(15):1194-1199.

12. Mohammed Al-Shafaee, Yousuf Al-Kaabi, Yousuf Al-Farsi, et al. Pilot study on the prevalence of abuse and mistreatment during clinical internship: a cross-sectional study among first year residents in Oman. BMJ Open. 2013;3:e002076.

13. Quine L. Workplace bullying in junior doctors: questionnaire survey. BMJ. 2002;324(7342):878-879.

14. Iftikhar R, Tawfiq R, Barabie S. Interns' perceived abuse during their undergraduate training at King Abdul Aziz University. Adv Med Educ Pract. 2014;5:159-166.

15. Alshahrani M, Dhafery B, Al Mulhim M, Alkhadra F, Al Bagshi D, Bukhamsin N. Factors influencing Saudi medical students and interns' choice of future specialty: a self-administered questionnaire. Adv Med Educ Pract. 2014;5:397-402.

16. Lambert TW, Goldacre MJ. Views of doctors in training on the importance and availability of career advice in UK medicine. Med Educ. 2007;41(5):460-466.

17. Jackson C, Ball JE, Hirsh W, Kidd JM. Informing choices: the need for career advice in medical training. Cambridge, UK: National Institute of Careers Education and Counselling; 2003.

18. Teo AR, Harleman E, O'Sullivan PS, Maa J. The key role of a transition course in preparing medical students for internship. Acad Med. 2011;86(7):860-865.

19. Allen PI, Colls BM. Improving the preregistration experience: the New Zealand approach. BMJ. 1994;308(6925):398-400.

20. Brennan N, Corrigan O, Allard J, et al. The transition from medical student to junior doctor: today's experiences of tomorrow's doctors. Med Educ. 2010;44(5):449-458.

21. Dare A, Fancourt N, Robinson E, Wilkinson T, Bagg W. Training the intern: the value of a pre-intern year in preparing students for practice. Med Teach. 2009;31(8):e345-e350.

22. Elizabeth JE, Hughes S. An assessment of the preregistration year experience. Br Med J (Clin Res Ed). 1986;293(6561):1559.

23. Hannon FB. A national medical education needs' assessment of interns and the development of an intern education and training programme. Med Educ. 2000;34(4):275-284.

24. Chang JC, Odrobina MR, McIntyre-Seltman K. Residents as role models: the effect of the obstetrics and gynecology clerkship on medical students' career interest. J Grad Med Educ. 2010;2(3):341-345.

25. Lam CY, Cheung CS, Hui AS. Factors influencing the career interest of medical graduates in obstetrics and gynaecology in Hong Kong: a crosssectional questionnaire survey. Hong Kong Med J. 2016;22(2):138-143.

26. Turner G, Lambert TW, Goldacre MJ, Barlow D. Career choices for obstetrics and gynaecology: national surveys of graduates of 1974-2002 from UK medical schools. BJOG. 2006;113(3):350-356.

27. Premadasa IG, Shehab D, Al-Jarallah KF, Thalib L. Frequency and confidence in performing clinical skills among medical interns in Kuwait. Med Teach. 2008;30(3):e60-e65.

28. Eley DS. Postgraduates' perceptions of preparedness for work as a doctor and making future career decisions: support for rural, non-traditional medical schools. Educ Health. 2010;23(2):374.

29. Blumenthal D, Gokhale M, Campbell EG, Weissman JS. Preparedness for clinical practice: reports of graduating residents at academic health centers. JAMA. 2001;286(9):1027-1034.

30. Nkabinde TC, Ross A, Reid S, Nkwanyana NM. Internship training adequately prepares South African medical graduates for community service-with exceptions. S Afr Med J. 2013;103(12):930934.

31. Gome JJ, Paltridge D, Inder WJ. Review of intern preparedness and education experiences in General Medicine. Intern Med J. 2008;38(4):249-253.

32. Illing JC, Morrow GM, Rothwell nee Kergon CR, et al. Perceptions of UK medical graduates' preparedness for practice: a multi-centre qualitative study reflecting the importance of learning on the job. $B M C$ Med Educ. 2013;13(1):1. 
Advances in Medical Education and Practice

Dovepress

\section{Publish your work in this journal}

Advances in Medical Education and Practice is an international, peerreviewed, open access journal that aims to present and publish research on Medical Education covering medical, dental, nursing and allied health care professional education. The journal covers undergraduate education, postgraduate training and continuing medical education

including emerging trends and innovative models linking education, research, and health care services. The manuscript management system is completely online and includes a very quick and fair peer-review system. Visit http://www.dovepress.com/testimonials.php to read real quotes from published authors.

Submit your manuscript here: http://www.dovepress.com/advances-in-medical-education-and-practice-journal 